\title{
Antibacterial Activity, Penicillinase Stability and Inducing Ability of Different Penicillins
}

\author{
By R. KNOX AND J. T. SMITH \\ Department of Bacteriology, Guy's Hospital Medical School, London, S.E. 1
}

(Received 22 September 1961)

\begin{abstract}
SUMMARY
There are now at least three main types of antibacterial activity shown by different penicillins - the ordinary penicillin $\mathrm{G}$ type, the type shown by methicillin active against penicillinase-producing staphylococci and the. 'broad spectrum' type of activity shown by $\alpha$-aminobenzylpenicillin.

The inducing capacity of different penicillins can be measured by the concentration required for maximal or half maximal induction, which gives the Michaelis (induction) constant, or by the total amount of enzyme eventually produced. But either of these methods of determining inducing capacity may give misleading results with penicillins which may be easily hydrolysed during the induction process.

Of the penicillins used methicillin is by far the best inducer-but it is uncertain how much this is due to a true 'inducing affinity' and how much a result of its resistance to hydrolysis.
\end{abstract}

\section{INTRODUCTION}

The isolation and crystallization of 6-aminopenicillanic acid from the fermentation liquor of Penicillium chrysogenum by Batchelor, Doyle, Nayler \& Rolinson (1959) opened the way to the synthesis of large numbers of new penicillins which it had not been possible to produce previously by microbiological methods. Already several new penicillins have been produced commercially and rival claims have been made in some cases for products with not very different antibacterial activities. Two of these new penicillins, methicillin and $\alpha$-aminobenzylpenicillin, have shown antibacterial activity of a quite different kind from that shown by penicillin $G$. It is thus no longer possible to speak of the penicillin type of antibacterial spectrum without qualification, and we can certainly no longer assume that sensitivity or resistance to one penicillin applies to others. The interpretation of laboratory sensitivity tests in the case of penicillins is complicated by the fact that some organisms have enzymes which destroy the antibiotics. It is, therefore, important to know with any new penicillin how stable it is to 'penicillinases' which may be produced by different organisms against which it is likely to be used. Some microorganisms show 'inherent' (Knox \& Smith, 1961) resistance to penicillin of a nonpenicillinase type; for example many strains of Escherichia coli and Proteus spp. are inherently resistant to penicillin G, though they may be quite sensitive to the 'broad. spectrum' penicillin, $\alpha$-aminobenzylpenicillin (Rolinson \& Stevens, 1961). In addition some penicillins are more capable of inducing penicillinase in organisms brought into contact with them than others. For example, methicillin has been found to be a better inducer of staphylococcal penicillinase than penicillin $\mathbf{G}$. 
(Rolinson, Stevens, Batchelor, Cameron-Wood \& Chain, 1960; Knox, 1960; Steinman, $1961 a$ ).

We have investigated six new penicillins and 6-aminopenicillanic acid with regard to their antibacterial activity, their stability to staphylococcal penicillinase and their ability to induce penicillinase in staphylococci. The results of these experiments are here reported.

\section{METHODS}

Penicillins. Penicillin G was obtained from Glaxo Laboratories Ltd. (Greenford, England), penicillin V, phenethecillin ('Broxil'), methicillin ('Celbenin'), $\alpha$-aminobenzyl penicillin ('Penbritin') and 6-aminopenicillanic acid from Beecham Research Laboratories (Brockham Park, Surrey), and phenoxypropyl penicillin from Pfizer Limited (Folkestone, Kent).

Measurement of antibacterial activity. Most of the bacterial cultures used were freshly isolated from clinical material but in some cases stock strains were used. Cultures were inoculated into nutrient broth and incubated overnight. One drop $(0.02 \mathrm{ml}$.) of undiluted broth culture or of various dilutions was dropped either into liquid media or on to nutrient agar plates containing serial dilutions of the antibiotic under investigation. In some experiments, in which large numbers of plates were required, volumes of about $0.01 \mathrm{ml}$. were inoculated by means of the phagetyping machine described by Tarr (1958) as a replicating device. Inoculated tubes or plates were incubated overnight at $37^{\circ}$ and again for a second day.

Source of staphylococcal penicillinase. The culture used was the E3 penicillinaseproducing strain of Staphylococcus aureus previously described (Knox, 1960; Knox \& Smith, 1961). This strain (of phage type 77) was originally isolated before the start of treatment from a lesion in the chest wall of one of the first patients to be treated with methicillin.

Measurement of penicillinase stability of different penicillins. For determining the stability of different penicillins to staphylococcal penicillinase a suspension of organisms grown overnight at $37^{\circ}$ in the presence of methicillin $(0.5 \mu \mathrm{g} . / \mathrm{ml}$.) as an inducing agent was mixed in equal parts in $1 \mathrm{oz}$. bottles with the appropriate penicillin in a final concentration of $2 \mathrm{mg} . / \mathrm{ml}$. Sodium $p$-chlormercuribenzoate was added to 0.001 м to prevent further induction of penicillinase during the experiment (Steinman, 1961 $a, b$ ). The reagents were pre-warmed and the reaction followed at $37^{\circ}$ in a water bath. Samples of $2 \mathrm{ml}$. were taken at intervals and the amount of penicillin remaining determined by the hydroxylamine method of Boxer \& Everett (1949) by estimation of the colour with an EEL (Evans Electroselenium Ltd., Harlow, Essex) colorimeter and comparison with a previously prepared standard curve.

As the molecular weights of the different penicillins used are about 350-400 the initial concentration of $2 \mathrm{mg}$. $/ \mathrm{ml}$. was equivalent to $\mathrm{M} / 175$ to $\mathrm{M} / 200$. With 6 -aminopenicillanic acid, however, with a molecular weight of 216 , the substrate concentration was about $0.01 \mathrm{M}$.

\section{Induction of penicillinase}

To determine the optimal conditions for induction, preliminary experiments were done with methicillin because of its known high inducing ability. Short periods of induction were used in order to separate as far as possible induction from growth and 
to minimize secondary changes and breakdown of the inducing agent which might occur in broth if induction were greatly prolonged.

Concentration of micro-organisms. Staphylococcus aureus strain E3 was inoculated into infusion broth and after overnight incubation the cocci were centrifuged down, washed with broth and resuspended at various optical densities in broth at $37^{\circ}$. Volumes of $19.5 \mathrm{ml}$. were placed in $25 \mathrm{ml}$. bottles and induced with methicillin $\left(0.5 \mu \mathrm{g} . / \mathrm{ml}\right.$.) contained in $0.5 \mathrm{ml}$. broth by shaking at 100 cycles $/ \mathrm{min}$. at $37^{\circ}$. After $1 \mathrm{hr}$., further induction was prevented by the addition of $p$-chlormercuribenzoate to

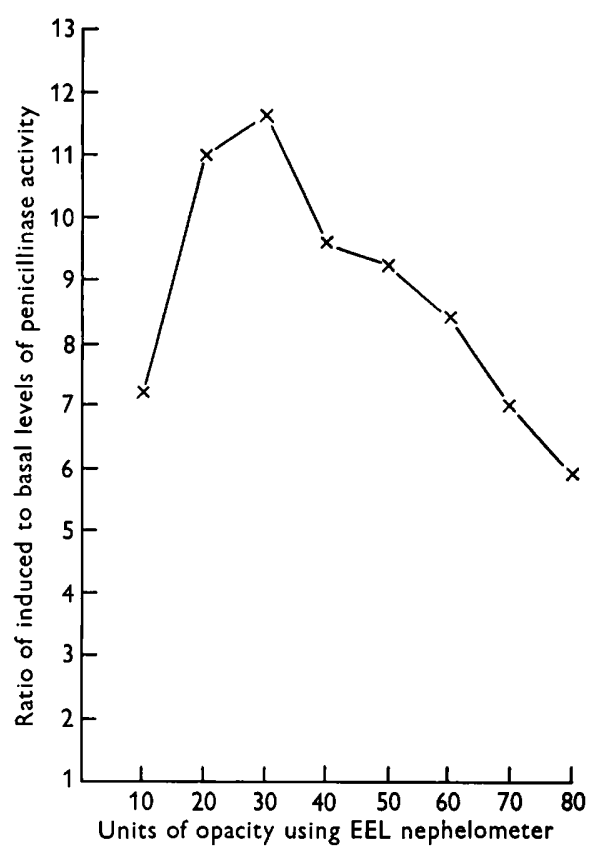

Fig. 1

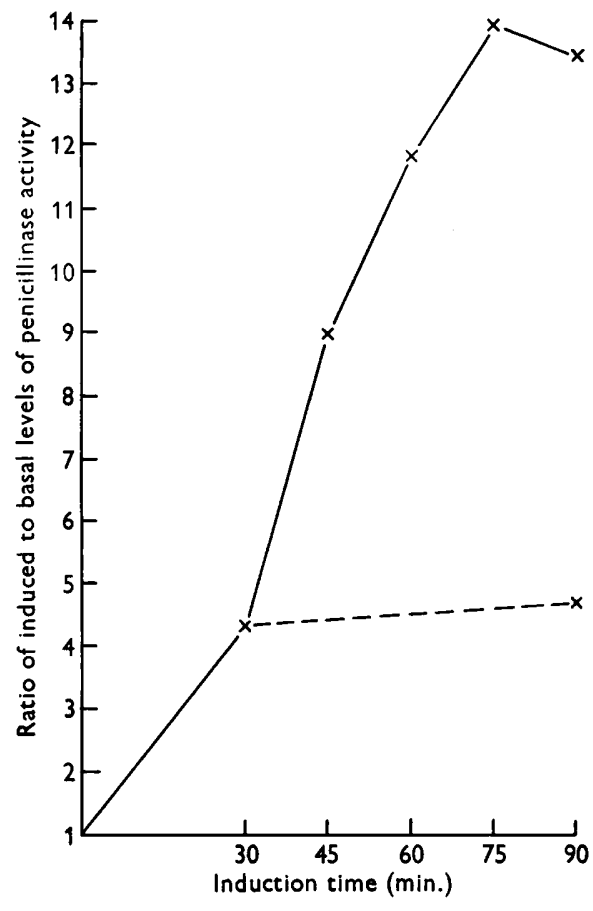

Fig. 2

Fig. 1. Effect of varying the initial concentration of organisms on the amount of penicillinase obtained during induction.

Fig. 2. Effect of varying the induction time on the amount of penicillinase obtained during induction.

0.001 $\mathrm{M}$, since Henry \& Housewright (1947) found that $0.001 \mathrm{~m} p$-chlormercuribenzoate had no effect on penicillinase activity, and Steinman $(1961 a, b)$ found that it stopped any further induction of penicillinase in staphylococci. (The results of Henry \& Housewright were confirmed by testing the action of $0.002 \mathrm{M} p$-chlormercuribenzoate for $2 \mathrm{hr}$. at $37^{\circ}$ on the intracellular penicillinase of staphylococci defatted by the method of Gilson \& Parker (1948). The defatted organisms when incubated with $0.002 \mathrm{M} p$-chlormercuribenzoate destroyed penicillin at the same rate as untreated defatted organisms.)

The organisms were then centrifuged and washed with $0.001 \mathrm{~m} p$-chlormercuribenzoate in broth, centrifuged and resuspended in $0.001 \mathrm{~m} p$-chlormercuribenzoate in broth at an optical density of 10 units measured by an EEL nephelometer. This 
corresponded to $3.3 \times 10^{7} \mathrm{cocci} / \mathrm{ml}$. $10 \mathrm{ml}$. of a solution $(4 \mathrm{mg} . / \mathrm{ml}$.) of penicillin $\mathrm{G}$ in $0.001 \mathrm{~m} p$-chlormercuribenzoate in broth at $37^{\circ}$ were then added to $10 \mathrm{ml}$. of the induced organisms at $37^{\circ}$ and the initial rate of hydrolysis of penicillin by the induced cocci was determined as described above. The increase of penicillinase over the basal level was determined; the results are shown in Fig. 1. It can be seen that the maximum increase in penicillinase occurred when the organisms were induced at an initial optical density of 30 units which corresponds to $7 \times 10^{7}$ cocci $/ \mathrm{ml}$. (It should be noted that with the EEL nephelometer the number of 'units' is proportional to the logarithm of the viable count.)

Period of induction. To determine the optimal time for induction, a culture of Staphylococcus aureus E3 grown overnight in broth was centrifuged and the deposit resuspended in broth at $37^{\circ}$ to give an optical density of 30 units measured by the EEL nephelometer, and then induced with methicillin $(0.5 \mu \mathrm{g} . / \mathrm{ml}$.) for different periods of time. Induction was then stopped with $p$-chlormercuribenzoate and the increase of penicillinase above the basal value determined as described above. The results are shown in Fig. 2. It can be seen that the maximal increase in penicillinase occurred when the organisms were induced for $75 \mathrm{~min}$. at $37^{\circ}$. The dotted line shows the effect of adding $p$-chlormercuribenzoate to make a final concentration of $0.001 \mathrm{M}$ at $30 \mathrm{~min}$. and continuing to shake at $37^{\circ}$ in the presence of the inducing agent until $90 \mathrm{~min}$. As can be seen from Fig. 2 this concentration of $p$-chlormercuribenzoate prevented further appreciable increase of penicillinase.

\section{Induction constants}

Induction constants (Pollock, 1957) for the different penicillins were determined by finding the concentration of inducer needed to cause maximal and half maximal increase in amount of penicillinase above the basal value. The optimal conditions for induction as determined above, with methicillin as standard, were used for the various penicillins in the following way. Each concentration of the penicillin being tested in $0.5 \mathrm{ml}$. broth was added to $19.5 \mathrm{ml}$. of suspension of organisms at an optical density of 30 units measured by an EEL nephelometer. The organisms were induced for $75 \mathrm{~min}$. at $37^{\circ}$, with shaking at $100 \mathrm{cycles} / \mathrm{min}$. Induction was then stopped with $0.001 \mathrm{M} p$-chlormercuribenzoate, the organisms centrifuged down, washed and resuspended with $0.001 \mathrm{M} p$-chlormercuribenzoate in broth to an optical density of 10 units. Of this suspension $10 \mathrm{ml}$. were then mixed at $37^{\circ}$ with $10 \mathrm{ml}$. of benzyl penicillin solution ( $4 \mathrm{mg} . / \mathrm{ml}$. in $0.001 \mathrm{M} p$-chlormercuribenzoate in broth) and the rate of penicillin breakdown determined by the hydroxylamine method. The maximum rate being taken as $100 \%$, the rates due to other concentrations of inducer were calculated accordingly. The concentration of inducer necessary to cause $50 \%$ of the maximum increase in penicillinase was then calculated graphically by interpolation.

\section{RESULTS}

\section{Antibacterial activity}

The antibacterial activity of the different penicillins is shown in Table 1. Penicillin $\mathbf{G}$ was active against Gram-positive cocci but with penicillinase-producing staphylococci it was almost completely inactive against large inocula though highly active against small inocula. In general penicillin $\mathbf{G}$ showed little activity against 
Gram-negative rods, though a few species were moderately susceptible (e.g. Salmonella typhi and some strains of Haemophilus influenzae). Penicillin V showed much the same type of spectrum. Against some strains of sensitive staphylococci it was even more active than penicillin $\mathrm{G}$, but against some strains of $\boldsymbol{H}$. influenzae and other Gram-negative organisms it was much less effective. Phenethecillin had a similar spectrum; it was slightly less effective than penicillin $\mathbf{V}$ or penicillin $\mathbf{G}$ against most Gram-positive and Gram-negative organisms, but showed greater activity than penicillin $\mathrm{V}$ or penicillin $\mathrm{G}$ against moderate inocula of penicillinaseproducing staphylococci. Phenoxypropyl penicillin had slightly greater activity

Table 1. Antibacterial activity of different penicillins

\begin{tabular}{|c|c|c|c|c|c|c|c|}
\hline \multirow[b]{2}{*}{ Micro-organism } & \multicolumn{7}{|c|}{ Minimum inhibitory concentration $(\mu \mathrm{g} . / \mathrm{ml})}$. \\
\hline & $\mathbf{G}$ & $\mathbf{V}$ & $\begin{array}{l}\text { Phenethe- } \\
\text { cillin }\end{array}$ & $\begin{array}{c}\text { Penicillin } \\
\text { phenoxy- } \\
\text { propyl }\end{array}$ & $\begin{array}{l}\text { Methi- } \\
\text { cillin }\end{array}$ & $\begin{array}{c}\alpha \text {-Amino } \\
\text { benzyl }\end{array}$ & 6APA \\
\hline Staphylococcus aureus (Oxford) & 0.02 & $0 \cdot 02$ & 0.03 & 0.08 & 1 & $\mathbf{0 \cdot 2}$ & 一 \\
\hline $\begin{array}{l}\text { S. aureus (5 penicillinase nega- } \\
\text { tive strains) }\end{array}$ & $0 \cdot 02$ & 0.01 & $0 \cdot 03$ & $0 \cdot 07$ & $\mathbf{1}$ & $0 \cdot 6$ & - \\
\hline \multicolumn{8}{|l|}{$\begin{array}{l}\text { S. aureus E3 (penicillinase pro- } \\
\text { ducing) }\end{array}$} \\
\hline $15 \times 10^{6}$ cells & $>1000$ & $>100$ & $>1000$ & $>1000$ & $7 \cdot 5$ & $>\mathbf{2 0 0}$ & 500 \\
\hline $15 \times 10^{4}$ cells & 250 & $>100$ & $\mathbf{2 5 0}$ & $62 \cdot 5$ & $3 \cdot 7$ & 200 & 250 \\
\hline $15 \times 10^{2}$ cells & $\mathbf{7 \cdot 5}$ & $3 \cdot 1$ & $\mathbf{3 \cdot 7}$ & $1 \cdot 8$ & $3 \cdot 7$ & $12 \cdot 5$ & $\mathbf{2 5 0}$ \\
\hline 15 cells & $<0.9$ & $0 \cdot 8$ & $1 \cdot 8$ & $<0.9$ & $\mathbf{3} \cdot \boldsymbol{7}$ & $6 \cdot 2$ & 125 \\
\hline Streptococcus pyogenes & $0 \cdot 005$ & $0 \cdot 01$ & $0 \cdot 2$ & 0.03 & $0 \cdot 2$ & 0.02 & - \\
\hline Strep. pneumoniae & 0.005 & $0 \cdot 01$ & 0.005 & 0.01 & $0 \cdot 05$ & $0 \cdot 1$ & 一 \\
\hline Strep. viridans & 0.02 & $0 \cdot 05$ & $0 \cdot 1$ & $0 \cdot 4$ & $0 \cdot 9$ & $0 \cdot 1$ & - \\
\hline Haemophilus influenzae A. 36 & $0 \cdot 9$ & $7 \cdot 5$ & 15 & 15 & $7 \cdot 5$ & 0.4 & - \\
\hline A. 37 & $1 \cdot 8$ & $7 \cdot 5$ & $7 \cdot 5$ & $7 \cdot 5$ & $3 \cdot 7$ & $0 \cdot 4$ & - \\
\hline A. 40 & $0 \cdot 2$ & $1 \cdot 8$ & $\mathbf{3} \cdot \mathbf{7}$ & $\mathbf{3} \cdot \mathbf{7}$ & $1 \cdot 8$ & $0 \cdot 2$ & - \\
\hline Escherichia coli A. 1 & 62 & $>250$ & $>\mathbf{2 5 0}$ & $>\mathbf{2 5 0}$ & $>\mathbf{2 5 0}$ & $7 \cdot 5$ & - \\
\hline A. 2 & 31 & 125 & $\mathbf{2 5 0}$ & $>\mathbf{2 5 0}$ & $>\mathbf{2 5 0}$ & 31 & - \\
\hline A. 10 & 125 & $>250$ & $>250$ & 一 & $>\mathbf{2 5 0}$ & 15 & 一 \\
\hline Salmonella typhi* & $7 \cdot 5$ & 62 & 250 & - & 250 & $0 \cdot 4$ & - \\
\hline Proteus sp. A. 4 & $1 \cdot 8$ & 31 & 250 & - & - & 0.9 & 一 \\
\hline Pseudomonas sp. & $>\mathbf{2 5 0}$ & $>250$ & $>250$ & - & $>\mathbf{2 5 0}$ & $>250$ & 一 \\
\hline
\end{tabular}

* Similar figures have been obtained for other salmonellae and shigellae.

than phenethecillin against penicillinase-producing staphylococci but the difference was not great and against very large inocula of these it seemed to be no more effective than phenethecillin, penicillin $G$ or penicillin $V$. The two penicillins of outstandingly different activity were methicillin and $\alpha$-aminobenzylpenicillin. Methicillin, although in general much less active than penicillin $\mathbf{G}$ against most sensitive cocci and even more inactive against Gram-negative bacilli, was almost equally active against both penicillinase-producing and penicillin-sensitive staphylococci in a concentration of $1-4 \mu \mathrm{g} . / \mathrm{ml}$. Its effect against penicillinase-producing staphylococci was almost independent of inoculum size, a feature which distinguished it sharply from all the other penicillins. $\alpha$-Aminobenzylpenicillin was rather less effective than penicillin $\mathrm{G}$ against the Gram-positive cocci but considerably more effective against many Gram-negative rods. Thus three main types of spectrum were 
seen with the penicillins tested-the typical penicillin $\mathbf{G}$ spectrum showing activity mainly against Gram-positive cocci, the methicillin type of spectrum showing greatly decreased activity against most micro-organisms as compared with penicillin $\mathbf{G}$ but unique activity against penicillinase-producing staphylococci, and the 'broad spectrum' activity shown by $\alpha$-aminobenzylpenicillin.

\section{Stability of different penicillins to staphylococcal penicillinase}

Table 2 shows the initial rates of hydrolysis of the different penicillins by staphylococcal penicillinase. It can be seen that the 'broad spectrum' $\alpha$-aminobenzylpenicillin was the most easily hydrolysed; next came penicillin $\mathrm{V}$, then penicillin $\mathrm{G}$. Phenethecillin and phenoxypropyl penicillin were hydrolysed almost as fast as penicillin G. The most resistant of all was methicillin which was not appreciably hydrolysed by staphylococcal penicillinase in the conditions of our experiments. 6-Aminopenicillanic acid was somewhat more rapidly hydrolysed than methicillin but was much more resistant than all the others. However, Batchelor, CameronWood, Chain \& Rolinson (1961) pointed out that while at neutral pH values and at fairly low concentrations 6-aminopenicillanic acid is much more stable to staphylococcal penicillinase than is penicillin $\mathrm{G}$, at suitable $\mathrm{pH}$ values and at optimal substrate concentration they can both be destroyed at similar rates.

Table 2. Rate of destruction of different penicillins by staphylococcal penicillinase

$\begin{array}{lc} & \begin{array}{c}\text { Initial rate } \\ \text { of destruction } \\ \mu \mathrm{g} . / \mathrm{ml} . / \mathrm{min} .\end{array} \\ \alpha \text {-Aminobenzylpenicillin } & 23 \cdot 0 \\ \text { Penicillin V } & 12 \cdot 8 \\ \text { Phenethecillin } & 11 \cdot 6 \\ \text { Penicillin G } & 11 \cdot 6 \\ \text { Phenoxypropyl penicillin } & \mathbf{8 \cdot 2} \\ \text { 6-Aminopenicillanic acid } & 0 \cdot 14 \\ \text { Methicillin } & 0 \cdot 09\end{array}$

\section{Induction of penicillinase}

Using cultures of the penicillinase-producing strain of Staphylococcus aureus E3 induced with different concentrations of different penicillins, we determined the concentrations of each of these for half maximal and maximal induction and also the increase in the amount of penicillinase activity over the control basal value (see Methods). The results are shown in Figs. 3 and 4, and Table 3.

It can be seen that all the penicillins tested acted as inducers, but that the best inducer was methicillin giving an 'induction constant' (Pollock, 1957) of 0.27 $\mu \mathrm{g} . / \mathrm{ml}$. for half-maximal induction. Thus, of the penicillins tested, the best inducer was the one least easily hydrolysed by staphylococcal penicillinase (see Tables 2 and 3) but 6-aminopenicillanic acid, which was not much less resistant to hydrolysis than methicillin, was less effective as an inducer. If the concentration of 6-aminopenicillanic acid required for half-maximal induction is taken as the criterion of inducing ability then 6-aminopenicillanic acid under the conditions used was not as good an inducer as the much more easily hydrolysable phenethecillin or phenoxypropyl penicillin (see also Tables 2 and 3). 
Table 3. Inducing ability of different penicillins

Penicillin V

$$
\begin{aligned}
& \text { Concentration } \\
& \mu \mathrm{g} \cdot / \mathrm{ml} \text {. to } \\
& \text { give maximal } \\
& \text { induction }
\end{aligned}
$$

300
100
100
30
10
10
3

Concentration
$\mu \mathrm{g} . / \mathrm{ml}$. to
give half
maximal
induction

$6 \cdot 6$

$9 \cdot 6$

$2 \cdot 2$

$0 \cdot 72$

3. 0

0.36

0.27

\section{Ratio of} induced to basal penicillinase activity at maximum
$12 \cdot 4$

$11 \cdot 1$

$26 \cdot 8$

15.5

$16 \cdot 3$

$26 \cdot 8$

$36 \cdot 0$

Summary of the data presented in Figs. 3 and 4 together with the maximal amount of penicillinase formed in relation to the basal level determined in the same experiments.

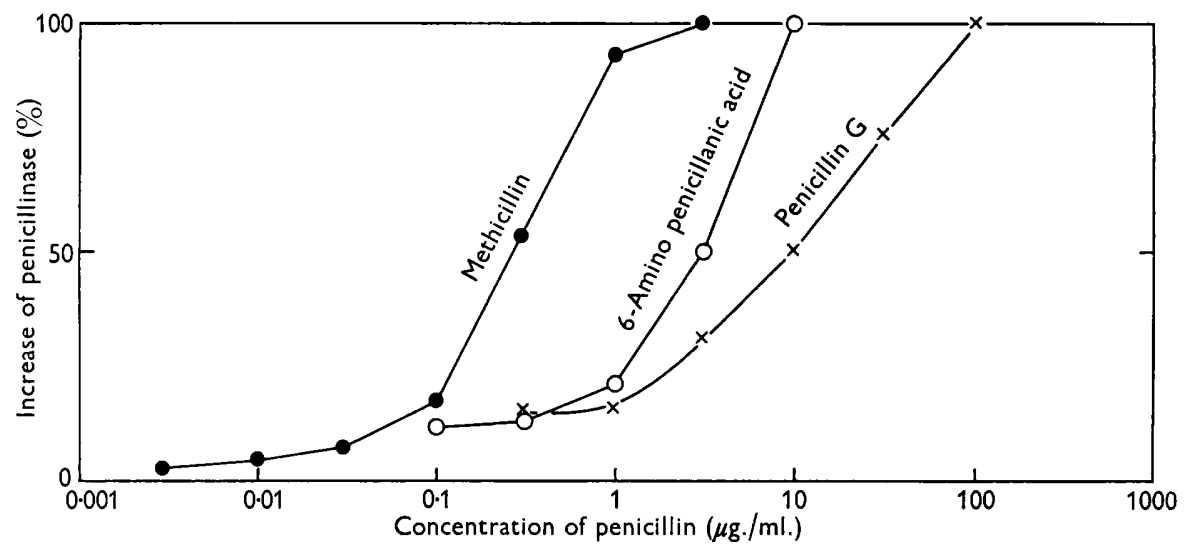

Fig. 3. Effect of concentration of antibiotic during induction on yield of penicillinase using 6-aminopenicillanic acid, methicillin and penicillin $\mathbf{G}$.

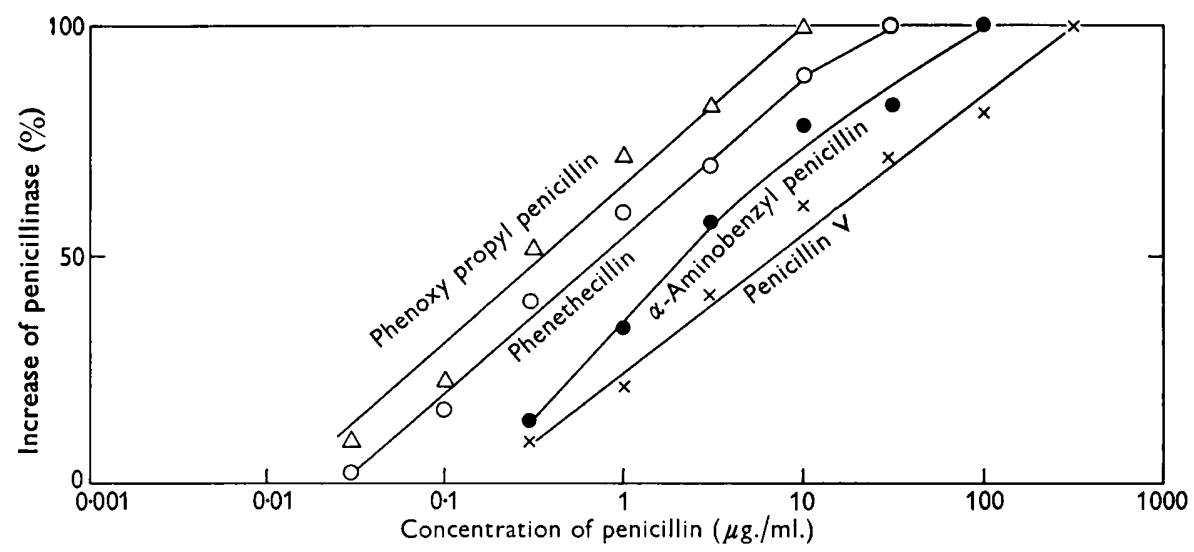

Fig. 4. Effect of concentration of antibiotic during induction on yield of penicillinase using phenethecillin, $\alpha$-aminobenzyl penicillin, phenoxypropyl penicillin and penicillin $\mathrm{V}$. 


\section{DISCUSSION}

With an inducing agent which is not a substrate it is fairly easy to determine the concentration required to give maximal or half maximal induction. But with a penicillin rapidly hydrolysed by penicillinase it is difficult to ensure optimal conditions for induction. Steinman $(1961 a, b)$ distinguishes between the affinity of the inducer for the enzyme and the total amount of enzyme which can eventually be formed. Estimates of this affinity as measured by induction constants agree fairly well with those that Steinman obtained for methicillin, 6-aminopenicillanic acid and penicillin G. However, the total amount of enzyme formed was considerably less in our experiments. This could be expected to vary with the conditions used especially if different strains of penicillinase-producing staphylococci differ greatly in their 'constitutive' penicillinase and in their capacity for induction.

We have found that with the most easily hydrolysed penicillin, $\alpha$-aminobenzylpenicillin, the yield of penicillinase in our experimental conditions was significantly increased above 'maximal' when the concentration of antibiotic known to give maximal induction (100 $\mu \mathrm{g} . / \mathrm{ml}$.) was added both initially and halfway through the period of induction. Thus the apparent maximal concentration as determined in one set of experimental conditions does not necessarily represent the true capacity of the organisms to produce penicillinase. Even if we attempt to overcome this difficulty by repeated small additions of an easily hydrolysable penicillin its true status as an inducer in comparison with a stable inducer such as methicillin is difficult to define.

An attempt has been made to relate the antibacterial activity of different penicillins, their penicillinase stability and their ability to induce penicillinase in staphylococci by means of a diagrammatic model (Knox, 1961). The fact that methicillin is highly resistant to staphylococcal penicillinase may be due to the poorness of fit between it and active centres on the penicillinase molecule. Nevertheless, it is a good inducer of the enzyme-hence it seems that the requirements for induction may be less stringent than those for a good substrate of the enzyme. Steric hindrance may also account for the relatively poor antibacterial activity of methicillin except against penicillinase-producing staphylococci. On the other hand, the combined Gram-positive and Gram-negative activity of $\alpha$-aminobenzylpenicillin may be, partly at least, due to the closeness of fit between its molecule and receptors on the surface of the bacterial cell. A similar closeness of fit between it and the penicillinase molecule may account for the rapidity with which it is hydrolysed. But with each new penicillin discovered it is important not only to know how easily it is hydrolysed by penicillinases from different sources, but also to study the possibility of breakdown by other mechanisms such as the amidases (Rolinson et al. 1960) which are known to be widely distributed among micro-organisms.

We are grateful to Beecham Research Laboratories for supplies of methicillin, phenethecillin, $\alpha$-aminobenzylpenicillin and 6-aminopenicillanic acid, to Pfizer Limited for phenoxypropyl penicillin used in this work, and to Miss B. Whittamore for valuable technical help. 


\section{REFERENCES}

Batchelor, F. R., Cameron-Wood, J., Chain, E. B. \& Rolinson, G. N. (1961). 6-Aminopenicillanic acid. V. 6-Aminopenicillanic acid as a substrate for penicillinase and an inducer of penicillinase formation. Proc. roy. Soc. B, 154, 514.

Batchelor, F. R., Doyle, F. P., Nayler, J. K. \& Rolinson, G. N. (1959). Synthesis of penicillin : 6-aminopenicillanic acid in penicillin fermentation. Nature, Lond. 183, 257.

Boxer, G. E. \& Everett, P. M. (1949). The colorimetric determination of benzyl penicillin. Analyt. Chem. 21, 670.

Gilson, Betty St C. \& Parker, R. F. (1948). Staphylococcal penicillinase: characteristics of the enzyme and its distribution. J. Bact. 55, 801.

Henry, R. G. \& Housewright, R. D. (1947). Studies on penicillinase. II. Manometric methods of assaying penicillinase and penicillin, kinetics of the penicillinase-reaction and the effects of inhibitors on penicillinase. J. biol. Chem. 167, 559 .

KNox, R. (1960). A new penicillin (BRL 1241) active against penicillin-resistant staphylococci. Brit. med. J. 2, 690.

Knox, R. (1961). A survey of new penicillins. Nature, Lond. 192, 492.

Knox, R. \& Sмiтh, J. T. (1961). The nature of penicillin resistance in staphylococci. Lancet, ii, 520.

Pollock, M. R. (1957). Activity and specificity of inducers of penicillinase production in Bacillus cereus, strain NRRL 569. Biochem. J. 66, 419.

Rolinson, G. N., Batchelor, F. R., Butterworth, D., Cameron-Wood, J., Cole, M.. Eustace, G. C., Hart, M. V., Richards, M. \& Chain, E. B. (1960). Formation of 6-Aminopenicillanic acid from penicillin by enzymic hydrolysis. Nature, Lond. 187. 236.

Rolinson, G. N. \& Stevens, S. (1961). Microbiological studies on a new broad spectrum penicillin ('Penbritin'). Brit. med. J. 2, 191.

Rolinson, G. N., Stevens, S., Batchelor, F. R., Cameron-Wood, J. \& Chain, E. B. (1960). Bacteriological studies on a new penicillin-BRL 1241. Lancet, ii, 564.

Steinman, H. G. (1961 $a$ ). A biochemical comparison of 6-aminopenicillanic acid, benzyl penicillin and 2,6-dimethoxyphenyl-penicillin. Proc. Soc. exp. Biol., N.Y. 106, 227.

Steinman, H. G. $(1961 b)$. Factors modifying induced formation of penicillinase in Staphylococcus aureus. J. Bact. 81, 895.

TARR, H. A. (1958). Mechanical aids for the phage-typing of Staphylococcus aureus. Mon. Bull. Minist. Hlth Lab. Serv. 17, 64.

\section{Note added in proof}

Doyle et al. (1961) have described a new series of isoxazolyl penicillins which are resistant to both acid and penicillinase and possess high antibacterial activity in vivo and in vitro. One of these, 5-methyl-3-phenyl-4-isoxazolylpenicillin (BRL 1400, P12) was tested for inducing ability. It was found to be a much more powerful inducer than methicillin. The maximal increase in penicillinase was $55 \cdot 8$ times the basal level at a concentration of $0.3 \mu \mathrm{g} . / \mathrm{ml}$., while the concentration required for half maximal induction was $0 \cdot 019 \mu \mathrm{g} . / \mathrm{ml}$.

Doyle, F. P., Long, A. A. W., Nayler, J. H. C. \& Stove, E. R. (1961). New penicillins stable towards both acid and penicillinase, Nature, Lond. 192, 1183. 